\title{
(Geo)políticas da Percepção: Limite, de Mário Peixoto, e Uma Página da Loucura, de Kinugasa Teinosuke
}

\author{
Andre Keiji Kunigami' \\ https:/orcid.org/0000-0002-2809-696X
}

I - University of North Carolina Chapel Hill, USA

Resumo: O artigo faz uma análise comparada de dois filmes considerados marcos globais da vanguarda "periférica" do entreguerras, cujas trajetórias apresentam muitos pontos em comum: Limite, de Mário Peixoto (1931), e Uma Página da Loucura (Kurutta Ichipēji), de Kinugasa Teinosuke (1926). Propomos uma leitura pós-colonial da fenomenologia fílmica, atentando à materialidade dos filmes e à forma como dão a ver o próprio dispositivo fílmico. Partindo dos discursos que constituíram o fascínio local sobre os filmes como exemplares de um regime de percepção moderno e universal, sugerimos que, por meio da sua própria constituição material, os filmes propõem uma contra-(geo)política temporal inerente à dimensão corporal da percepção fílmica.

Palavras-chave: modernismos periféricos; Limite; Uma Página da Loucura; fenomenologia do cinema; universalidade.

Abstract: (Geo)politics of perception: Limite, by Mário Peixoto, and Uma Página da Loucura, by Kinugasa Teinosuke - The article engages a comparative analysis of two films considered global landmarks of the "peripheral" interwar avantgarde, whose paths display many common aspects: Limite, by Mário Peixoto (1931), and A Page of Madness, by Kinugasa Teinosuke (1929). We argue for a post-colonial reading of film-phenomenology, focusing on their materiality and the ways in which they show the very filmic apparatus. Starting from the discourses that constituted the local fascination with the films as exemplary of a modern and universal perceptual regime, we argue that through their very material constitution, the films put forth a counter-(geo)politics of time inherent to the corporeal dimension of filmic perception.

Keywords: peripheral modernisms; Limite; A Page of Madness; film-phenomenology; universality. 


\section{Introdução: Fósseis}

Limite (PEIXOTO, 1931) e Uma Página da Loucura (Kurutta Ichipēji, TEINOSUKE, 1926) são dois objetos mitológicos. Quando lançados, na passagem dos anos 1920 aos 1930, respectivamente no Brasil e no Japão, ambos foram saudados como eventos cinematográficos únicos e inéditos nos seus contextos nacionais. A longa desaparição à qual ambos foram submetidos ajudou a inscrevê-los mais fundo na história do cinema como obras-primas perdidas, ancoradas em discursos críticos que os colocaram como evidências da globalidade de suas modernidades locais. Por meio da experimentação estética e do entusiasmo com as possibilidades do próprio aparato fílmico, eles foram recebidos como uma resposta local - ou, por vezes, uma síntese - às vanguardas históricas que haviam emergido da Europa, como símbolos de uma realização de modernidade. O meio por vir, o discurso crítico afirmava, havia finalmente chegado aos espaços periféricos por meio desses filmes.

A narrativa do filme Uma Página da Loucura se passa em um hospital psiquiátrico. O protagonista é o zelador do hospital (Inoue Masao), um ex-marinheiro que batalha contra o sentimento de culpa pela condição mental de sua esposa (Nakagawa Yoshie), internada no mesmo hospital por ter afogado seu filho enquanto o marido estava no mar. A sua condição mental torna-se um empecilho para o casamento da filha do casal (lijima Ayako) com um rico jovem burguês. Gradualmente, o filme mostra a perda da sanidade do zelador, assombrado pela loucura da mulher, enquanto os espectadores experimentam uma série de delírios visuais, o que acaba por posicionar ambos, personagem e espectadores, do lado dos pacientes confinados. A história em si, contudo, é praticamente ininteligível. O aspecto mais importante do filme é a experiência estética produzida pela montagem e câmera, que constituem a loucura não apenas como uma representação, mas preponderantemente como um regime de percepção: montagem rápida, justaposições, imagens distorcidas, movimentos bruscos.

O filme de Mário Peixoto, Limite, é também um filme sobre percepção e restrições perceptuais - apesar de o tom geral do filme ser, em vez da montagem rápida de Kinugasa, o de uma temporalidade lenta e dilatada, ainda que modulada por arroubos de movimentos abruptos e repetitivos. O enredo, também esparso, narra a história de duas mulheres (Tatiana Rey, Carmen Santos) e um homem (Raul Schnoor) à deriva em um barco em mar aberto. Filmado em Mangaratiba, sul do estado do Rio de Janeiro, a presença da natureza aberta, no entanto, evoca uma situação em que os corpos não encontram escapatória física - o que é refletido na própria estrutura do filme, por meio das repetições e longas durações. Por meio da montagem e do uso da câmera, os filmes impõem uma manipulação do visível que 
nos direciona para sua própria materialidade. Denominaremos essas construções formais de "o corpo do filme", usando o termo proposto por Vivian Sobchack (1992, p. 171) para descrever "a fisiologia e anatomia da tecnologia cinematográfica". Por meio de seus corpos, eles operam um agenciamento que leva a visibilidade orgânica (do espectador) e técnica (da câmera) a um limiar. A questão então seria: onde esse limiar se rompe?

De fato, o corpo é o foco da política sensória dos filmes. Ambos narram histórias sobre restrições físicas e desorientações afetivas, representando a loucura em uma experimentação estética que evidencia o dispositivo fílmico e sua presença. Um experimento, como descreveu Gertrude Koch (2014), age sobre o próprio corpo de quem observa, abrindo um espaço de diferença entre investimento afetivo e experiência corpórea. Suas explorações das possibilidades da percepção fílmica aproximam, assim, os corpos na tela não apenas dos corpos dos espectadores: para além da inscrição fílmica, os filmes aqui analisados também operam uma convergência -- necessária entre o filme como corpo e o corpo do espectador --, engendrada por sua arquitetura interpelativa. A temporalidade mediada dos filmes é tornada constantemente visível, revelando a política corporal que se entende na especificidade dos corpos que animam: a materialidade fílmica (o corpo fílmico), o espaço visível garantido aos corpos na tela (corpos no filme), e os corpos dos espectadores.

Os aspectos comuns que unem os discursos críticos e o corpo fílmico das duas obras são numerosos. Amparados por campanhas publicitárias na mídia impressa, que os descreviam como inéditas realizações nacionais de caráter universal, ambos foram recebidos de maneira superlativa, mantendo-se cobertos por uma aura de fascínio mitológico até hoje. Após décadas de ausência material, período no qual eles produziram uma lacuna ostensivamente presente nos imaginários fílmicos nacionais, eles reemergiram aos olhos do público nos anos 1970: em 1971, Kinugasa acidentalmente encontrou o filme, que havia sido dado como incendiado em 1950, quase completo (com a exceção de um rolo perdido) em sua casa; e o filme de Peixoto teve seu longo processo de restauração concluído em 1977. Nesse processo, ambos os filmes tiveram partes de seu corpo perdidas. Porém, as décadas da presença material incerta parecem ter aprofundado a inscrição desses filmes nas narrativas históricas de suas modernidades locais.

"Encontrar um filme perdido é como descobrir um novo corpo celeste", escreveu o crítico e teórico Yomota Inuhiko (2015, p.181) em recente ensaio sobre Uma Página da Loucura, revelando o fascínio duradouro por esse objeto da vanguarda. ${ }^{1}$ Corpo celeste que construiu seu lugar nas historiografias do cinema como "um puro fóssil da gloriosa vanguarda", nas palavras de Yomota (2015, p.198): menos um filme, mais

\footnotetext{
1 Todas as traduções do japonês, inglês e espanhol são minhas.
} 
um objeto-relíquia a ser "exibido" e "apreciado", assim como Limite, votado o "melhor filme brasileiro de todos os tempos" pela Associação Brasileira de Críticos de Cinema (Abraccine), em 2015, e reverenciado com o lançamento em 2017 pelo World Film Project de Martin Scorsese. Uma Página da Loucura é "um filme que pode ser considerado como o ápice da história do cinema japonês, em perfeitas condições. [Sua descoberta] foi um grande evento que preencheu um elo perdido na história do cinema" (YOMOTA, 2015, p.181). Limite, por sua vez, é muitas vezes visto como "a melhor contribuição [do Brasil] para a vanguarda internacional" (VIEIRA, 1987, p.137). Desde suas primeiras exibições, os discursos tendem a repetir o arrebatamento com os filmes: a conquista do "universal". Este artigo tem como objetivo revisitar, em paralelo, as tensões que esses filmes retêm no seu próprio corpo fílmico, as quais os põem em fricção com a própria geopolítica da percepção ativada pela vanguarda que Ihes garantiu valor de culto. ${ }^{2}$

O valor de culto dos filmes de Peixoto e Kinugasa viria das suas capacidades de superar sua localidade, alcançando uma experiência estética que libertaria seus espectadores da sua particularidade geo-cultural como num "encaixe" no paradigma da vanguarda central. ${ }^{3}$ A fossilização desses filmes os transformou em monumentos - monumentos do cinema, mas também monumentos do ethos de uma modernidade periférica. Como lembra Nestor García Canclini (1989, p. 169-170), trata-se do esquema que entende "outras" modernidades como "um eco deferido e deficiente dos países centrais". O que nos guiará aqui serão as temporalidades dos filmes: ao explicitarem o dispositivo do cinema, ambos mostram, no nível sensório, a impossibilidade de tal esquema moderno. Assim, produzem uma contra-política temporal na relação entre o corpo de quem vê e o corpo do filme. ${ }^{4}$ Se, como Miriam Hansen (1999) sugere, nos anos 1920, todo cinema é reflexivo e estabelece uma relação com a experiência moderna, aqui examinaremos como as temporalidades propriamente fílmicas contrapõem-se aos investimentos geopolíticos direcionados ao cinema como dispositivo modernizante.

2 Os anos 1920 e 1930 constituem momentos ápices do discurso que equiparava "cinema" e "modernidade", condicionando um ao outro. Um fenômeno comum a todas as nações fora do eixo Europa-Estados Unidos, incluindo-se Brasil e Japão, foi o da retórica do "atraso": o cinema nacional estava "atrasado" por ser um cinema que retratava um país atrasado. Tal discurso foi amplamente difundido nas revistas ilustradas de cinema, como Cinearte e Para Todos, no Brasil, e Kinema Junpo ou Nihon Eiga, no Japão.

3 Jonathan Abel mostrou como os discursos críticos sobre Uma Página da Loucura posicionam o filme dentro das vanguardas como um "pôr-se em dia" com a Europa (ABEL, 2001, p. 74). Robert Stam (1995, p. 309), por sua vez, mapeou Limite dentro de uma cadeia de referências europeias para afirmar que, "num nível especificamente cinematográfico, Limite, apesar de não ser a ruptura experimental de Um Homem com uma Câmera, é razoavelmente audacioso".

4 Sobre a crítica temporal intrínseca ao cinema, ver Bliss Cua Lim, 2009. 


\section{O universal como não-mediação}

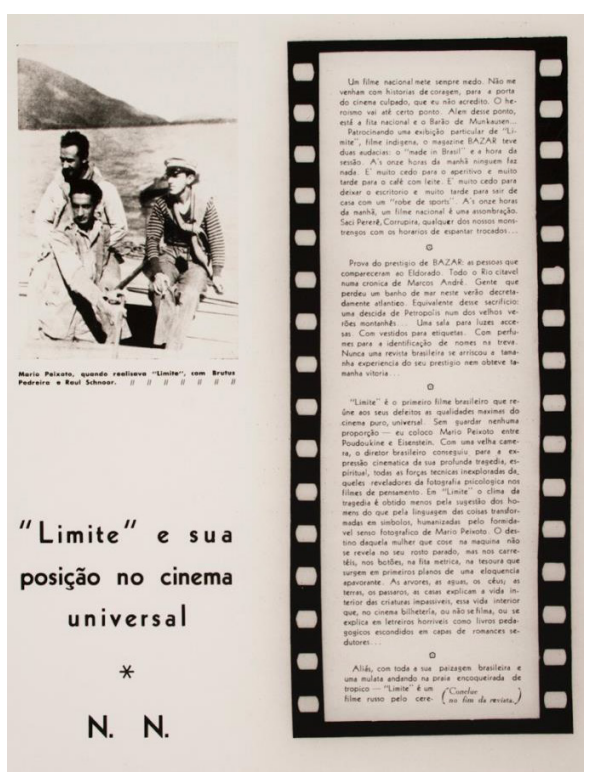

Fig. 1. Diário da Noite, 30 de janeiro de 1932

Como anunciado em 20 de junho de 1932 no Diário da Noite, Limite trazia a promessa de talhar um lugar para o Brasil no "cinema universal": "o primeiro filme brasileiro que reúne aos seus defeitos as qualidades máximas do cinema puro, universal" (Figura 1). Dois aspectos eram alardeados: o fato de que o filme foi feito no Brasil e o seu estilo experimental atento aos estímulos sensórios do cinema. Ecoando as posições defendidas por Octávio de Faria em $O$ Fan, nota-se a supremacia do imediatismo sensório da imagem visual, a defesa da supressão da palavra escrita e falada, a ênfase na duração e no ritmo. ${ }^{5}$ O próprio Faria organizaria a primeira exibição do filme em 17 de maio de 1931, no Cinema Capitólio do Rio de Janeiro. Em ensaio publicado em 17 de julho de 1931, em O Jornal, Faria defende que Peixoto haveria conseguido deslocalizar a natureza, evitando o "constrangimento" trazido pela representação comum da natureza exibida pelo cinema brasileiro. Se as paisagens naturais eram uma imagem-cliché do Brasil, Faria (1931) - evocando a noção de fotogenia, popularizada por Jean Epstein ${ }^{6}$ - elogia a capacidade de o corpo fílmico de Limite promover o escrutínio do mundo material em sua composição de duração e interrupção, "arrancando" a paisagem de seu lugar. Uma palmeira, dessa forma, pode se transformar em um poste de eletricidade, apontando a um só tempo para um símbolo

5 Ver os ensaios Faria publicados em O Fan: "O Scenario e o Futuro do Cinema", 1928-1929; "Contra o Film Fallado", 1929; "Eu Creio na Imagem", 1929. Para um resumo das posições estéticas de Faria, ver Xavier, 2017, pp. 243-259.

6 Faria, nas páginas de O Fan, deixa explícito o impacto que o conceito de fotogenia, em leitura bem particular, produz sobre sua teoria do cinema. 
da modernidade, para a montagem cinematográfica e para a condição de possibilidade do próprio cinema: a eletricidade (figuras 2 a 4). O texto descreve o filme de Peixoto como uma tensão entre a restrição operada pela câmera e o desejo de universalidade atrelado à natureza. Essa chave de leitura se mantém até hoje, como mostra o recente ensaio de Jens Andermann (2017), que lê o lugar da paisagem natural no filme de Peixoto como um espaço de produção do afeto. Mas, seguindo a própria ênfase dada tanto por Faria quanto por Peixoto, eu proponho uma leitura a partir da relação com a própria promessa da percepção fílmica: trata-se menos da natureza e mais da sua percepção tecnicamente mediada. É o próprio cinema, como promessa frustrada de superação do corpo em direção a um universal, que produz o afeto negativo. Para escapar da economia global do exotismo, a própria "anatomia do filme" mostra um desejo de universalidade por meio do fascínio narcísico com a sua própria existência como um experimento que agencia tecnologia e corpo por meio da percepção.

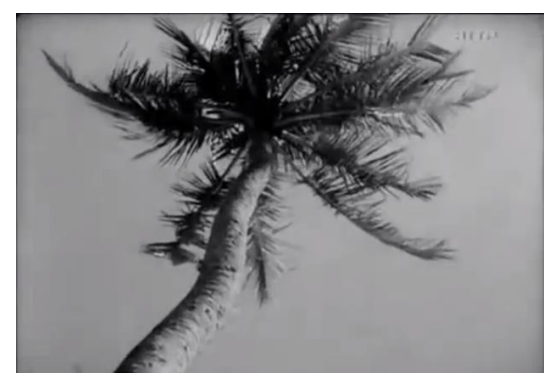

Fig. 2.

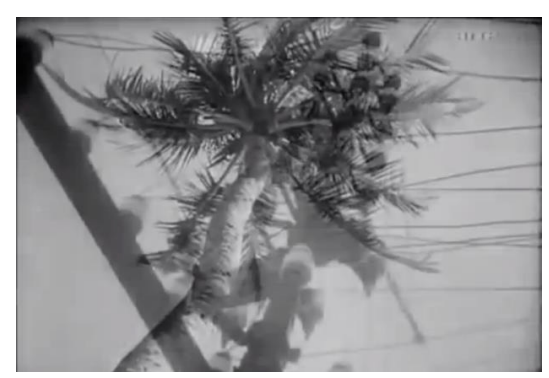

Fig. 3.

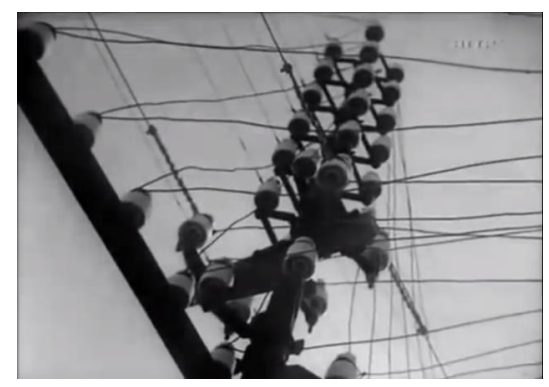

Fig. 4. 
Três décadas após o lançamento do filme, Peixoto escreveu um ensaio intitulado "Um Filme da América do Sul", publicado em 1965, sob o nome de Sergei Eisenstein, numa estratégia para atrair investidores para seu próximo projeto. ${ }^{7}$ Evocando a utopia Griffithiana de uma linguagem universal, Peixoto/Eisenstein (2000, p. 92) escreveu: "A América do Sul, de princípio desconhecida e estranha aos meus conhecimentos, me estende ela também, esta noite, e através da contrição de imagens, a tão perturbadora armadilha de uma linguagem universal". Aqui, Mário Peixoto deixa claro que a utopia universal é uma armadilha que, proponho, traduz-se temporalmente na espera, como um comentário sobre a própria mediação do cinema: a promessa da visão maquínica e externa ao corpo tão sonhada pelas vanguardas. Na dialética entre localidade e universalidade - a América do Sul tropical endereçada por um nome do cinema "universal" -, a convergência, no nível do desejo, entre a geopolítica da vanguarda e a própria anatomia do corpo fílmico é traduzida afetivamente como angústia: esperar sem alcançar. O filme destaca, como seu objeto, a sua desejada capacidade de ver. Um objeto que promete a libertação do olho em relação ao corpo, mas que encontra restrição na própria mediação tecnológica: a velocidade vem com repetição, visibilidade vem com imobilidade. A construção estética do filme torna-se, assim, um comentário sobre os próprios limites de sua empreitada. O filme narra na sua diegese e, ao mesmo tempo, performa no seu corpo o desejo de um olhar totalizante justamente por meio da sua impossibilidade.

É na figura da promessa performada pelo corpo fílmico que o filme de Kinugasa Teinosuke se encontra com o de Peixoto. Pesquisadores como Aaron Gerow (2008) e Yomota Inuhiko (2015) descreveram as transformações que o filme sofreu desde sua primeira exibição: dos 2.142 pés originais, a versão presente possui 1.617 pés, baixando de 103 para 78 minutos, na projeção original de 18 quadros por segundo. Hoje o filme consiste em mais de 800 planos, contabilizando 3,3 segundos por plano, significativamente mais rápido que o ritmo médio da narrativa clássica. Do primeiro negativo, passando pela sugestão do escritor Yokomitsu Riichi, que resultou na eliminação de todas as palavras, até o momento de redescoberta dos rolos perdidos, seguidos da exclusão de mais trechos pelo próprio Kinugasa, o que se subtraiu do filme foi sua "inteligibilidade" narrativa: a parte na qual o melodrama familiar se desenvolvia. O corpo fílmico que restou é o da experimentação sensorial, o "fóssil da vanguarda" como uma experiência de cinema "puro" e universal por seu investimento sensório. ${ }^{8}$

Em artigo de 1926 da revista Kinema Junpō, o famoso crítico marxista Iwasaki Akira (apud YOMOTA, 2015, p.192) escreveu sobre o filme: "este é o primeiro filme de qualidade internacional [sekaiteki] feito no Japão. [...] Mesmo que eu não tenha entendido

7 Apesar de já estabelecido como texto de Mário Peixoto, ainda há menções errôneas à autoria de Sergei Eisenstein, como no recente artigo de Andermann, 2017.

8 Aqui é importante lembrar que o conceito de "cinema puro" foi usado, em distintos lugares, para designar distintas formas cinematográficas. Apesar de ser o cinéma pur francês aquele que aparece como referência no filme de Kinugasa e seus colaboradores vanguardistas do grupo "Neo-sensorialista", no contexto de modernização do cinema japonês, "cinema puro" (no original, jun'eiga) dizia respeito ao sistema de coerência realista do cinema clássico. 
o enredo inicialmente, eu acho que o cinema, sendo mais imediato e não sobre histórias, de agora em diante, será algo que não necessita ser entendido à primeira vista [...]". O impacto corpóreo daquelas imagens, Iwasaki (apud YOMOTA, 2015, p. 192) sugere, foi constitutivo do seu modo de mediação: "Vendo Uma Página da Loucura, eu senti este medo corpóreo instintivo, meu corpo ficou tensionado, e meus olhos se encheram de lágrimas de alegria. Então eu senti um respeito por Kinugasa que eu não havia sentido antes por nenhum diretor no Japão. Ele conhece o cinema". O primeiro filme a trazer o "verdadeiro cinema" ao país foi menos "compreendido" do que "sentido". ${ }^{9}$ Sua modernidade residia na interseção entre dois modernismos: o cinema clássico defendido pelo Movimento do Cinema Puro (Jun'eigageki Undō) e o modernismo sensório defendido pelos "Neo-Sensorialistas" (Shinkankaku-ha), que se dedicavam ao debate estético na revista Bungei Jidai, contando com nomes como Kawabata Yasunari e Yokomitsu Riichi (o filme de Kinugasa foi a primeira produção fílmica promovida pelo grupo). Entre o que Miriam Hansen (1999) chamou de "modernismo vernacular" e um modernismo de vanguarda, ambos os paradigmas se encontravam no desejo pelo moderno traduzido no universal. É sabido também que o primeiro corte do filme possuía alguns intertítulos, os quais foram excluídos do corte final a pedido de Yokomitsu; escolha que Kinugasa explica como um respeito à imagem fílmica (eizō). Ele escreve:
[...] na primeira cena de Uma Página da Loucura, aquela com o hospital psiquiátrico à noite sob chuva pesada, as notas [do roteiro] dizem "chuva pesada, vertendo" [...] Então colocamos as notas repetidas vezes diante de nossos olhos e pensamos na tela. Ou, melhor, esperamos para que a imagem se desdobre por ela mesma. [...] Não é incomum que cenas escritas de forma simples nas notas vão gradualmente inchando-se em imagem (eizō). (KINUGASA, 1977, p. 73, minha ênfase)

Assim como Limite, Uma Página da Loucura fascinou pela sua natureza fílmica, entendida como a primazia da imagem, como notou Kinugasa na passagem acima, por sua capacidade de captar um movimento em latência. Como parte central do seu ideário histórico-estético, estava uma percepção sem mediações, numa relação direta com o mundo fenomênico "que não existe em relação a um sujeito", como descreveu Yokomitsu (1925, p. 4).

9 Jonathan Abel (2001) especula que o filme original, com todos os rolos, seria um filme estritamente narrativo. Apesar da ausência dos intertítulos ou qualquer inscrição verbal, Abel nos lembra que a narração do benshi, presente nas primeiras exibições, funcionava para trazer coerência e continuidade narrativa ao que hoje parece imagens deslocadas. Ele ainda especula um argumento culturalista, baseado numa diferença cognitiva do próprio espectador japonês, o qual, ele imagina, estaria "acostumado a combinar signos distintos tanto em cinema quanto na linguagem" (ABEL, 2001, p.78). Abel segue a suposição Orientalista de Eisenstein - de que os espectadores japoneses vivem um constante estado cognitivo de montagem pela sua língua -, sugerindo que a sutura do filme de Kinugasa se dava no próprio aparato cognitivo diferente do corpo japonês. Uma análise da recepção do filme, no entanto, contradiz tal hipótese orientalista. 
A interpelação não-mediada e direta como premissa do universal ganha contornos geopolíticos quando vemos o peso com o qual essa agenda foi recebida e promovida tanto por Chaplin Club e Neo-Sensorialistas, na busca por uma síntese histórica entre "modernos" e "atrasados". Irena Hayter (2017, p. 304) vê este ideal de percepção como uma expressão do desejo de purificação da visão dos outros sentidos corporais, construindo "uma sensação que é de certa forma abstrata, removida da materialidade carnal do corpo". O cinema seria, dessa maneira, parte do projeto de organizar politicamente os sentidos, na promessa de uma visão sem corpo. Investia-se no próprio aparato fílmico um desejo de supremacia da visão capaz de liberar o sujeito de sua fisicalidade, respondendo ao risco do que Mary Ann Doane (1980, p. 33-34) chamou de “corpo fantasmático" inerente ao cinema, ou seja, o corpo unificado tecnologicamente que carrega o latente risco de fragmentação. Em ambos os casos, o resultado é o oposto: o fantasma se faz presente.

\section{Dialéticas do controle: entre a pose e o gesto}

O fascínio de ambos os filmes, tanto o de Peixoto quando o de Kinugasa, por seu próprio ser filme revela, em última instância, um fascínio pelo movimento. Ambos procuram dar visibilidade a um movimento maquínico, engendrado pelo dispositivo fílmico. Dessa maneira, ambos expõem de forma fundamental o movimento tecnicamente produzido. Da passagem da imagem mental à imagem mecânica descrita por Kinugasa, o que ocorre é a emergência de um movimento entendido como autônomo e tecnológico. Trata-se de um ponto fundamental para a dialética do controle que subjaz à dialética do movimento fílmico, exposto por ambos os filmes: a relação entre espera e ação, desejo e descontrole.

Vivian Sobchack (1992, p. 61) argumenta que o cinema "tem ser, no sentido que ele age. Uma fotografia parada, no entanto, não age; antes, ela espera - como um vazio - para que nós a possuamos". Essa afirmação resume muito do debate fenomenológico sobre a ontologia fílmica. Sobchack descreve a relação ambígua que a fotografia estabelece com o tempo na forma de uma espera que, segundo sua tese, seria uma negação da experiência vivente. A qualidade de "vida" do cinema seria equivalente à sua capacidade de movimento, a qual se relacionaria diretamente com a experiência da "vitalidade": alguém se move porque possui um corpo, que é finito, situado e limitado. Nessa visão binária e negativa - segundo a qual a fotografia é aquilo que o cinema não é -, a fotografia seria o oposto da vida, o que Sobchack (1992, p. 58) lê como um desejo de infinitude. Nesse sentido, o argumento fenomenológico diz que a fotografia é uma espera por uma ação externa - uma fuga do próprio tempo - enquanto a duração fílmica representaria um habitar do devir temporal do presente.

Contudo, como nos lembra Joseph Vogl (2019), a espera é transitiva e intersticial, um estado limiar em que se age e se é submetido ao desejo: a espera requer um 
engajamento corpóreo. Assim como a espera não está fora do tempo - quase o oposto, é uma aguda experimentação do tempo -, o movimento fílmico não pode ser purificado da estase fotográfica. No seu cerne, encontra-se o fotograma parado. Apesar de ser entendido como a interrupção do movimento, o fotograma fílmico releva a estase não como prévia ou posterior ao movimento, mas como sua parte indiscernível. O fotograma - o qual Gilles Deleuze (1983, p. 83) chamou de "o elemento genético de qualquer percepção possível", já que é "inseparável da série que o faz vibrar" - não só contém a potencialidade do mover-se como é também a sua condição de visibilidade. Assim, aqui veremos como a oposição fenomenológica traçada por Sobchack (1992) se manifesta, antes, como uma tensão inerente à relação entre a tecnologia e o corpo de quem vê, por meio da busca obsessiva dos filmes por dar a ver um movimento que, em última instância, não está na imagem, mas sim no corpo que o sintetiza no momento da visão. Dessa maneira, movimento e estase encontram-se no próprio limiar visível da temporalidade do dispositivo, produzindo uma espera pela visibilidade.

A relação entre movimento e estase é central para os filmes de Kinugasa e Peixoto. Pode-se dizer que a imagem estática se encontra no cerne de suas explorações sobre o corpo fílmico e os limites da visibilidade do movimento: o desejo de ver o limiar entre estase e movimento constitui seus dispositivos de visibilidade. Seja pelo conflito entre as poses estáticas dos corpos e objetos, em Limite, seja na montagem rápida e nas distorções visuais ocasionadas pelos gestos descontrolados dos corpos loucos em Uma Página da Loucura, ambos os filmes exploram o seu próprio meio através da fronteira que define o mover-se. É na indiscernibilidade entre pose e gesto que os filmes entram num regime de pensar sobre si: como se buscassem o momento de emergência visível do movimento. O fotográfico - diferentemente do verbal, que é expurgado em prol da primazia universalizante do visível - paira como um fantasma sobre o desejo do livre movimento.

Kinugasa (1977, p. 64) narrou sua visita ao Hospital Psiquiátrico Matsuzawa, em Tóquio, como o momento em que percebeu o potencial dramático da loucura: "com a imagem da loucura humana como pano de fundo, não pode o drama emergir?, eu perguntei a Yokomitsu e Kawabata enquanto narrava a visita ao hospital, na noite do mesmo dia". Kinugasa (apud ABEL, 2001, p. 85) foi guiado, em sua visita, por Kure Shūzō, diretor da instituição e uma das figuras centrais na modernização da medicina no país. (Figura 5) 


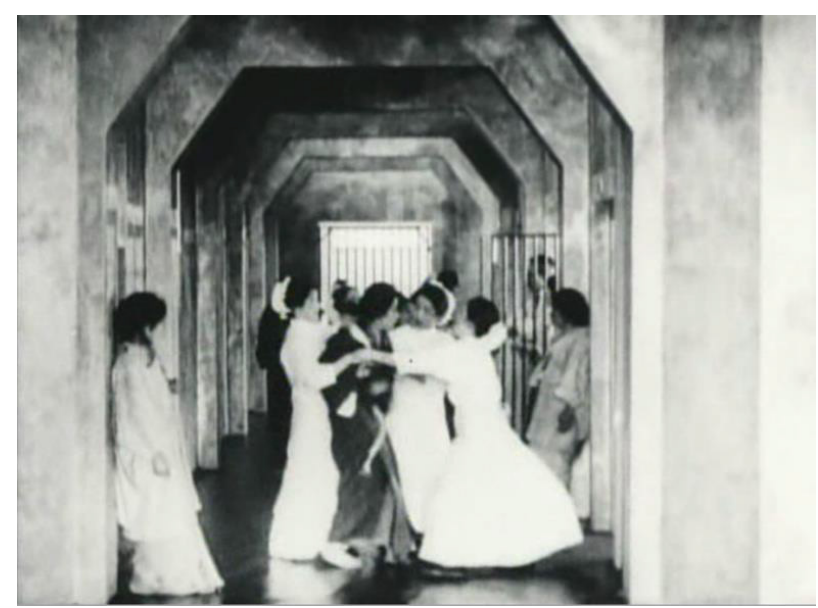

Fig. 5.

Como lembrou Yomota Inuhiko (2015, p. 226), "na base [da ideia de filmar a loucura], estava o entusiasmo de recriar da forma mais fiel possível, em cinema, os gestos e comportamentos dos loucos, seus movimentos descontínuos e espasmódicos, apresentando-os ao desejo escopofílico do público". A afinidade entre o fílmico e o gesto louco sugeria uma mútua atração na qual ambos elementos representavam distintas facetas da mesma modernidade. Também como um objeto da representação, a loucura funciona como maneira de explorar o meio fílmico, uma vez que sua visibilidade emerge precisamente em momentos de explosão de movimento, nos gestos dos corpos femininos do filme. O gesto louco se torna, assim, o local par excellence do fílmico: um exibicionismo do movimento por si só, revelando o corpo como um meio aderido à tecnologia que Ihe dava visibilidade.

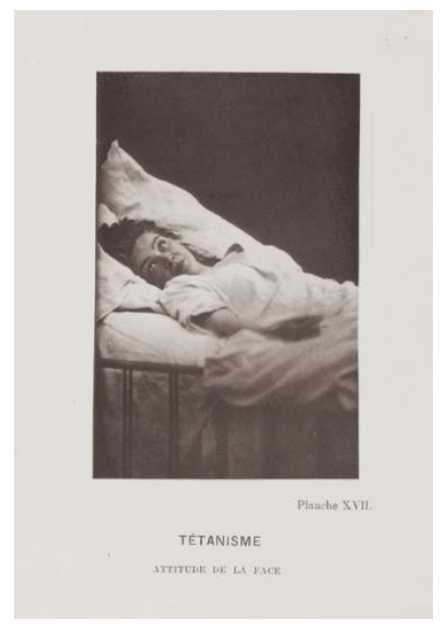

Fig. 6. "Atitude do Rosto." Iconographie Photographique de la Salpétrière, placa XXIII. 


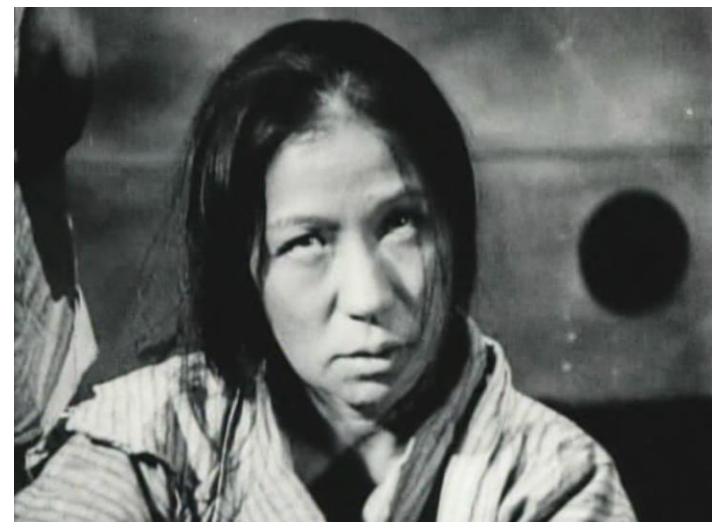

Fig. 7. Still de Uma Página da Loucura.

O filme apresenta uma espécie de catálogo da loucura, evocando as fotografias de Albert Londe das "histéricas" durante as sessões de Jean-Martin Charcot no hospital parisiense La Salpetrière, publicadas nos volumes Iconographie Photographique de la Salpetrière (1878-1880). As imagens ajudam a entender o que estava em jogo no filme de Kinugasa. Charcot, que foi o mentor de Freud e "descobridor da histeria", costumava orquestrar espetáculos voyeurísticos semanais centrados naqueles corpos femininos retorcidos, os quais Londe fotografava. Como Georges Didi-Huberman (2003, p. 3) coloca, a histeria nasceu de um espetáculo performativo organizado como um "evento de significantes". Nos catálogos de Charcot, o que se via era uma organização dos afetos projetados sobre os gestos congelados em pose: repugnância, melancolia, paixão, etc. No filme de Kinugasa, o mesmo impulso está presente (Figuras 6 e 7, acima; 8 e 9, abaixo):

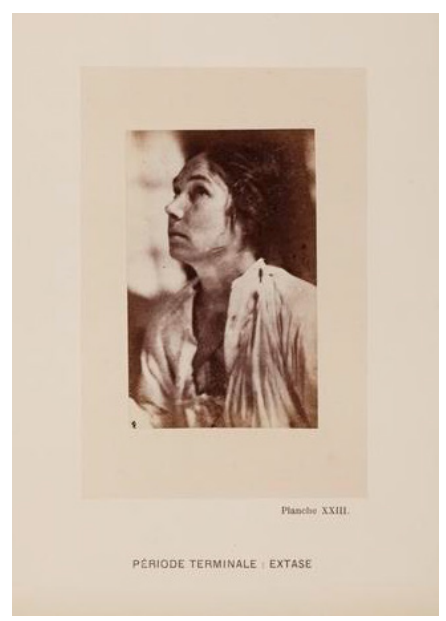

Fig. 8. "Período Terminal: Êxtase." Iconographie Photographique de la Salpétrière, placa XXIII. 


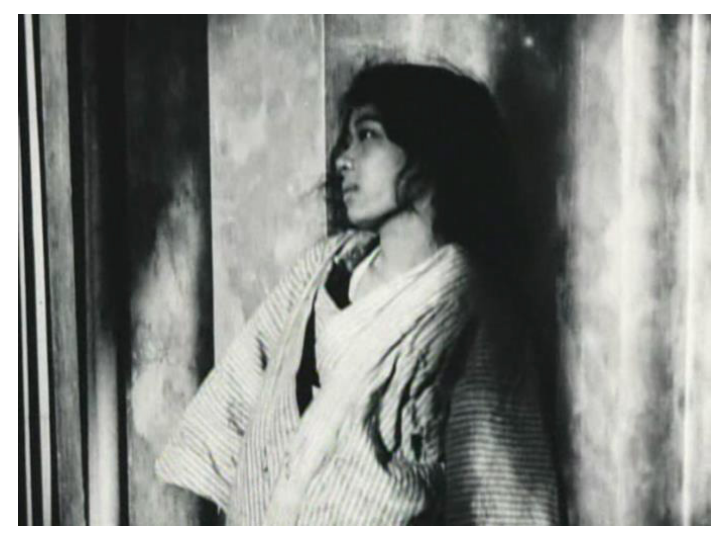

Fig. 9. Still de Uma Página da Loucura.

Mas ao investir duplamente na loucura como local e regime de visibilidade, o filme de Kinugasa leva o aparato sensorial dos espectadores ao limite da invisibilidade. Como Zoe Beloff (2008) atentou, a performance física da histeria, encenada para a captura fotográfica, testava os limites do dispositivo por sua resistência à pose. Mas, se a fotografia estática falsificava a visibilidade da loucura na encenação da pose, o filme de Kinugasa se coloca no extremo oposto e rejeita qualquer estabilidade em prol de uma ânsia pelo movimento. Ao responder à demanda de uma percepção universal e purificada central ao projeto modernista do filme, a natureza movente do corpo louco no filme também suprime a possibilidade de visibilidade: quanto mais absorvemos o movimento em direção a uma visão purificada, menos vemos (figura 10).

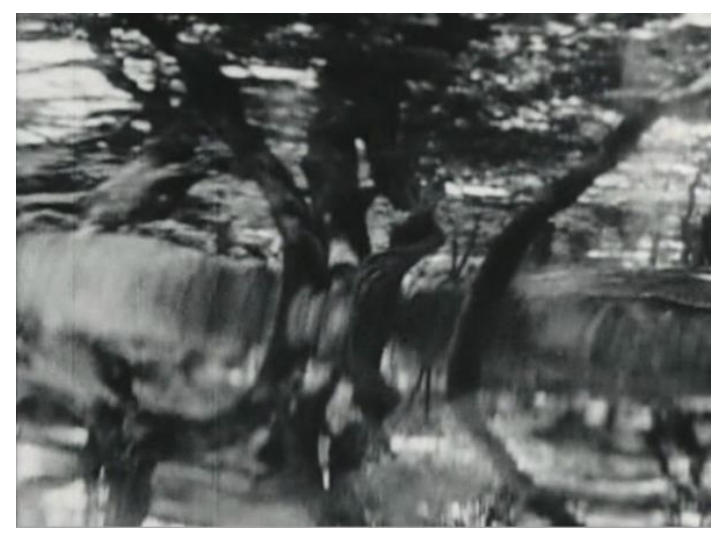

Fig. 10. Uma Página da Loucura.

O embate perceptual entre gesto e pose também é central ao filme de Peixoto. Dando ênfase ao ritmo, Limite se organiza em torno de uma relação problemática com 
a estase fotográfica, de forma a produzir a sensação de suspensão temporal. Para alcançar a sensação de se estar "além do tempo"10 o filme alonga seu olhar aos objetos, esticando o fotograma. Sob o mesmo ímpeto de explorar a pureza da percepção fílmica o movimento nascente -, Limite pode ser entendido igualmente como uma busca pela emergência do fílmico no fotográfico. Seu dispositivo de visibilidade torna-se, assim, uma espera pelo momento da aparição do movimento: mostrando o homem e as duas mulheres à deriva em mar aberto, sua narrativa torna-se uma metonímia do seu dispositivo de espera.

Uma fotografia também se encontra no cerne do filme de Peixoto. Como ele narrou, a ideia de Limite surgiu do encontro com uma fotografia produzida por André Kertész para a capa da revista ilustrada $V u$ (figura 11). A imagem, mostrando o rosto de uma mulher atrás de braços algemados de um homem, foi transposta visualmente para o primeiro (figura 12) e o último planos do filme, representando, como argumenta Mello (2007, p. 40), o seu tom afetivo geral. Novamente, uma imagem de uma mulher encarcerada: ambos os filmes nos lembram, como Andreas Huyssen (1986) apontou, que a mulher como perigo era uma recorrência modernista.

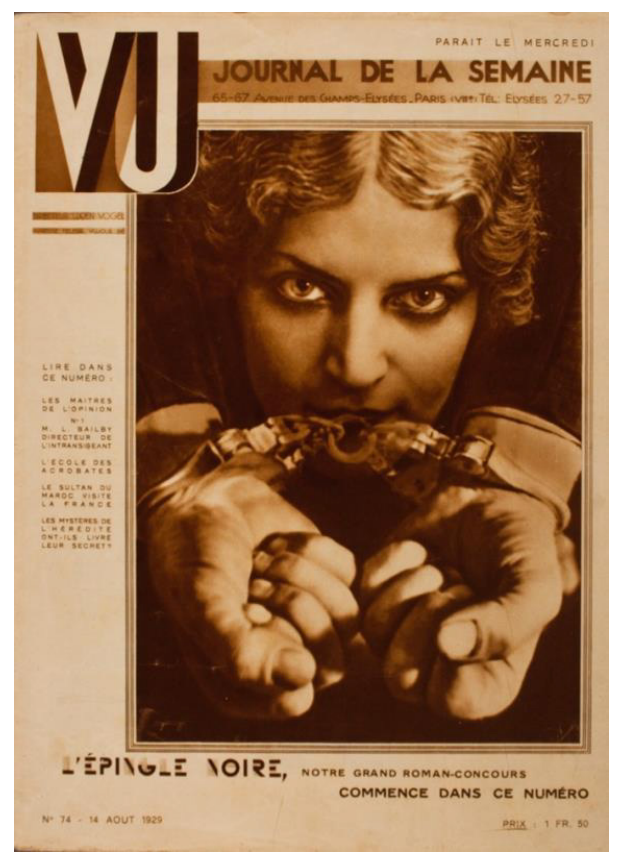

Fig. 11. fotografia de André Kertész na capa de $V u$

10 Saulo Pereira de Mello (2007, p.44) assim descreve essa sensação: "claramente, então, como que saímos do tempo - ou estamos além do tempo". 


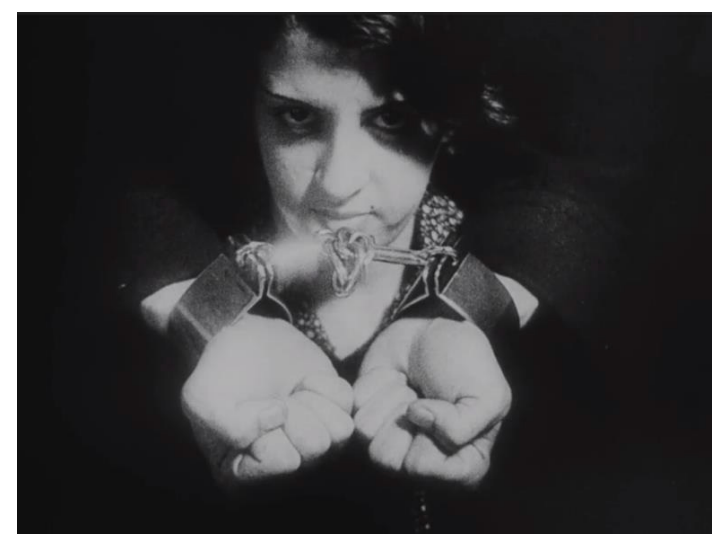

Fig. 12. abertura de Limite.

O filme funciona como uma observação demorada dos movimentos do mundo, tendo como centro a pose: a construção da separação visível entre movimento e não-movimento. Através de demorados close-ups, a câmera congela ou recorta corpos. Por vezes, vemos o escrutínio do mundo material como se a temporalidade da própria imagem o estivesse aprisionando em poses. O filme torna-se a sua própria capacidade de isolar o movimento: um raio de luz se destaca da superfície que ilumina, o leve tremor da beira da página do jornal, um tufo de cabelo sobre uma cabeça estática. O ponto aqui, paradoxalmente, é que esse dispositivo de visibilidade alcança uma não-visibilidade. Como afirmou José Carlos Avellar (2008), "[o] cinema, sugere Limite, torna o visível invisível, escurece, desfoca".

\section{Considerações finais}

Apesar do ideal da visão absoluta pensado por Octávio de Faria e o Chaplin Club, ou da visão não-mediada imaginada por Yokomitsu Riichi e os neo-sensorialistas, os filme de Peixoto e de Kinugasa performam tal percepção "purificada" como uma impossibilidade, cuja manifestação afetiva se dá na espera - na constante produção do invisível. Os experimentos arquitetados por Peixoto e por Kinugasa performam o seu fracasso como ontológico. Se os planos rápidos de Kinugasa evidenciam o atraso na percepção do espectador, as durações lentas de Peixoto evidenciam o atraso do dispositivo em satisfazer o desejo por movimento. Em ambos os casos, a não-convergência entre corpo e imagem revela que a temporalidade da percepção nunca é controlável. As promessas que os filmes ativam de uma universalidade incorpórea são constantemente frustradas.

Por meio dessas estruturas de frustração, os efeitos colaterais políticos abertos por ambos os "fósseis da vanguarda" são trazer o desejo modernista ao primeiro plano de seus experimentos como um fracasso. Fracasso que se dá por meio da própria percepção 
no corpo. É o dispositivo do cinema que revela que a visão é inescapavelmente corporificada: ela requer tempo e "atraso" para operar a síntese do movimento. Como Jimena Canales (2006) nos lembra, apenas vemos o movimento fílmico por conta da nossa incapacidade perceptiva - vemos porque vemos menos. O cinema, no seu limite, nos lembra da temporalidade corpórea da percepção. Menos como um exercício de mimese colonial, os filmes revelam a universalidade como uma impossibilidade ao deslocar a visão para dentro da temporalidade do corpo.

André Keiji Kunigami é doutor pela Cornell University e atualmente é pesquisador associado de pós-doutorado na University of North Carolina at Chapel Hill, junto ao Department of Romance Studies.

akeiji@gmail.com

\section{Referências}

ABEL, J. Different from Difference: Revisiting Kurutta Ichipeiji. In: Asian Cinema, v. 12 n. 2, 2001, pp. 72-96.

ANDERMANN, J. The Politics of Landscape. In: DELGADO, M.; HART, S.; JOHNSON, R. (Eds). A Companion to Latin American Cinema. West Sussex, UK; Malden, MA, EUA: John Wiley Ed, 2017, p. 133-149.

AVELLAR, J. C. O lugar sem limites. In: Cinémas d'Amérique latine [on-line], v. 16, 2008. Disponível em: http://journals.openedition.org/cinelatino/2055.

CANALES, J. Movement Before Cinematography: The High-Speed Qualities of Sentiment. In: Journal of Visual Culture, v. 5, n. 3, 2006, pp. 275-294.

CANCLINI, N. G. ¿Modernismo sin Modernización? In: Revista Mexicana de Sociología, v. 5, n. 3, 1989, pp. 163-189.

DELEUZE, G. Cinema 1: The Movement-Image. Minneapolis: University of Minnesotta Press, 1983.

DIDI-HUBERMAN, G. Invention of Hysteria: Charcot and the Photographic Iconography of the Salpêtrière. Cambridge, MA: MIT Press, 2003.

DOANE, M. A. Voice in the Cinema: the articulation of body and space. In: Yale French Studies. n. 26, 1980, pp. 33-50.

FARIA, O. Natureza e Rhitmo. O Jornal. 17 de julho de 1931.

. O Scenario e o Futuro do Cinema. O Fan, n.1-3, Agosto de 1928-Janeiro de 1929.

. Eu Creio na Imagem. O Fan, n.6, Setembro de 1929, pp. 3-4.

Contra o Film Fallado. O Fan, n.2, Outubro de 1928, p.3.

GEROW, A. A page of madness: cinema and modernity in 1920s Japan. Ann Arbor: University of Michigan Press, 2008. 
HANSEN, M. The Mass Production of the Senses: Classical Cinema as Vernacular Modernism. Modernism/Modernity. v. 6, n. 2, 1999, p. 59-77.

HAYTER, I. Figures of the Visual: Japanese Modernism, Technology, Vitalism. In: Positions: east Asia cultures critique, v. 25, n. 2, 2017, pp. 293-322.

HUYSSEN, A. Mass Culture as Woman. After the Great Divide: Modernism, Mass Culture, Postmodernism. Bloomington: Indiana University Press, 1986, pp. 44-62.

KINUGASA, T. Waga Eiga no Seishun: Nihon Eigashi no Ichi Sokumen. Toquio: Chūō Kōronsha, 1977.

$\mathrm{KOCH}, \mathrm{G}$. Film as experiment in animation: Are films experiments on human beings? In: New German Critique, v. 41 n. 2, 2014, pp. 97-109.

LIM, B. C. Translating time: cinema, the fantastic, and temporal critique. Durham: Duke University Press, 2009.

N.N. Limite e sua posição no cinema universal. Diário da Noite. 30 de janeiro de 1932.

PEIXOTO, M. Um Filme da América do Sul. In: MELLO, S. P. (Org). Mário Peixoto: Escritos sobre Cinema. Rio de Janeiro: Aeroplano, 2000, p. 85-94.

SOBCHACK, V. The Address of the Eye: a phenomenology of film experience. Princeton: Princeton University Press, 1992.

STAM, R. Margins of the Avant-garde. In: JOHSON, R.; STAM, R. (Eds). Brazilian Cinema. New York: Columbia University Press, 1995, pp. 306-327.

VIEIRA, J. L. A chanchada e o cinema carioca (1930-1955). In: RAMOS, F. (Org). História do Cinema Brasileiro. São Paulo: Art editora, 1987.

VOGL, J. On Tarrying. Kolkata: Seagull Books, 2019.

XAVIER, I. Sétima Arte: Um Culto Moderno. São Paulo: SESC, 2017.

YOKOMITSU, R. K. K. Bungei Jidai, v. 2, n.2, fevereiro de 1925.

YOMOTA, I. Kinugasa Teinosuke Kurutta Ichipeji to 1920nen dai. In: Shincho Monthly, v. 112, n. 11, 2015, pp. 179-232. 